\title{
Does Gender Equality work for Sustainable Development in Central Africa Countries? Some Empirical Lessons
}

By

Gérard Tchouassi ${ }^{1}$

\begin{abstract}
It is commonly argued that Central Africa countries need economic growth and gender equality to ensure economic well-being and improve the living standards of the population. This paper, based on the Kuznets curve associated to environmental analysis, aims to analyze the relationship between gender equality and sustainable development. The cross-sectional analysis, with data from 11 countries in Central Africa in 2010, was used. Results find a positive correlation between gender equality and sustainable development. When the Multidimensional poverty index increases, environmental problems reduce, translating the role of gender in sustainable development in all Central Africa countries.
\end{abstract}

\section{JEL Classifications: C23, Q38, Q56}

Key words: Gender, Inequality, Sustainable development, Environmental Kuznets curve

\section{Introduction}

Twenty years after the first Rio Summit in 1992, the international community once again in June 2012 was convened in Brazil to discuss environmental issues. Actors in the field of environment and sustainable development (SD) have scaled-up their meetings with hopes that proposals for a common African position on development be reached. Since October 2011, preparatory meetings have been organized by the African Union, the African Development Bank and the Economic Commission for Africa. Together, African environment ministers have adopted the African Consensus Statement on Rio+20. This declaration clearly emphasizes the necessity to strengthen commitments in the areas that are crucial for sustainable development in Africa. They include improving agricultural productivity and food security, promoting

${ }^{1}$ Department of economics, University of Yaoundé II Po Box: 1365 Yaoundé - Cameroon, Phone: (237) 33114781 (Home) Phone: (237) 99920998 (Cell) E-mail: tchouassigerard@yahoo.fr 
research and development, encouraging the use of biotechnology for sustainable development, and intensifying the fight against desertification and land degradation, among others. It is commonly argued that Central Africa countries need economic growth and gender equality to increase their well-being status and improve the standards of living of their populations. This will help fight poverty and vulnerability. But what are the effects of gender equality on the environment, precisely on the sustainable development?

The United Nations 1987 Brundtland Report defines sustainable development as development that meets the needs of the present without compromising the ability of future generations to meet their own needs. It contains within it two key concepts. The concept of 'needs', in particular the essential needs of the world's poor, to which overriding priority should be given; and the idea of limitations imposed by the state of technology and social organization on the environment's ability to meet present and future needs (United Nations, 1987). Sustainable development ties together concern for the carrying capacity of natural systems with the social challenges facing humanity. As early as the 1970s, the term "sustainability" was employed to describe an economy "in equilibrium with basic ecological support systems" (Stivers, 1976). Ecologists have also pointed to the limits of growth (Meadows et al., 1972), and have presented the alternative of a "steady state economy" (Daly, 1973) in order to address environmental concerns.

Development is considered here as well-being and the process of transforming the society. Some of the key indicators of well-being are: rate of poverty, peace, freedom, life expectancy at birth, adult illiteracy, access to health care services, access to safe water, access to sanitation, infant mortality rate, maternal mortality rate, prevalence of malnutrition, population estimates, gross domestic product (GDP) per capita (World Bank, 2008). The field of sustainable development can be conceptually broken into three constituent parts: environmental sustainability, economic sustainability and socio-political sustainability. Sustainable development is a contested concept, which influences how issues are formulated and actions proposed. It is presented as the intersection between the environment, society and economy, conceived as separate although connected entities. Giddings, Hopwood, and O'Brien (2002) argue that these are not unified entities. Rather, they are fractured and multi-layered, and can be considered at different spatial and geographical levels. The economy is often given priority in policies and the environment is viewed as apart from humans. Nevertheless, they are interconnected, with the economy dependent on society and the environment while human existence and society are dependent on, and 
within the environment. The separation of environment, society and economy often leads to a narrow techno-scientific approach, while issues to do with society that are most likely to challenge the present socio-economic structure are often marginalized.

Understanding gender means understanding opportunities, constraints and the impacts of change as they affect both men and women. Partnerships and equality between men and women are the basis of strong families and viable societies in a rapidly changing world. Women have been consistently excluded from decision-making across history and societies. Indeed, in all social groups women are being systematically discriminated against within systems of governance that allow for the dominance of a few social groups to the expense of others. It is such power structures that cause further imbalance, marginalization, suffering and conflict. Creating greater gender equity will contribute to building peaceful, democratic and prosperous societies.

Gender can be defined as the set of characteristics, roles and behavior patterns that distinguish women from men which are constructed not biologically, but socially and culturally. The sex of an individual is biologically determined, whereas gender characteristics are socially constructed, a product of nurturing, conditioning, and socio-cultural norms and expectations. These characteristics change over time and from one culture to another. The concept of gender refers not only to women and men but also to the relations of power between them and the other marginalized groups (for example the handicrafts group). Gender relations are constantly being renegotiated in the context of changing political, economic, social, and cultural environments at the local, national and international level (Sen Gita, 1999).

This paper is inspired from the environmental Kuznets curve hypothesis (EKC hypothesis) elaborated by Kuznets in 1955. This curve shows that as a country develops, there is a natural cycle of economic inequality driven by market forces which at first increases inequality, and then decreases it after a certain average income is attained. The Diagram 1 below shows an inverted $U$ curve. Since 1991, environmental Kuznets curves have become standard features in the technical literature of environmental policy (Yandle et al., 2002), though their application here is strongly contested (Roberts and Thanos, 2003). 
Diagram 1: Kuznets curve: an inverted U curve

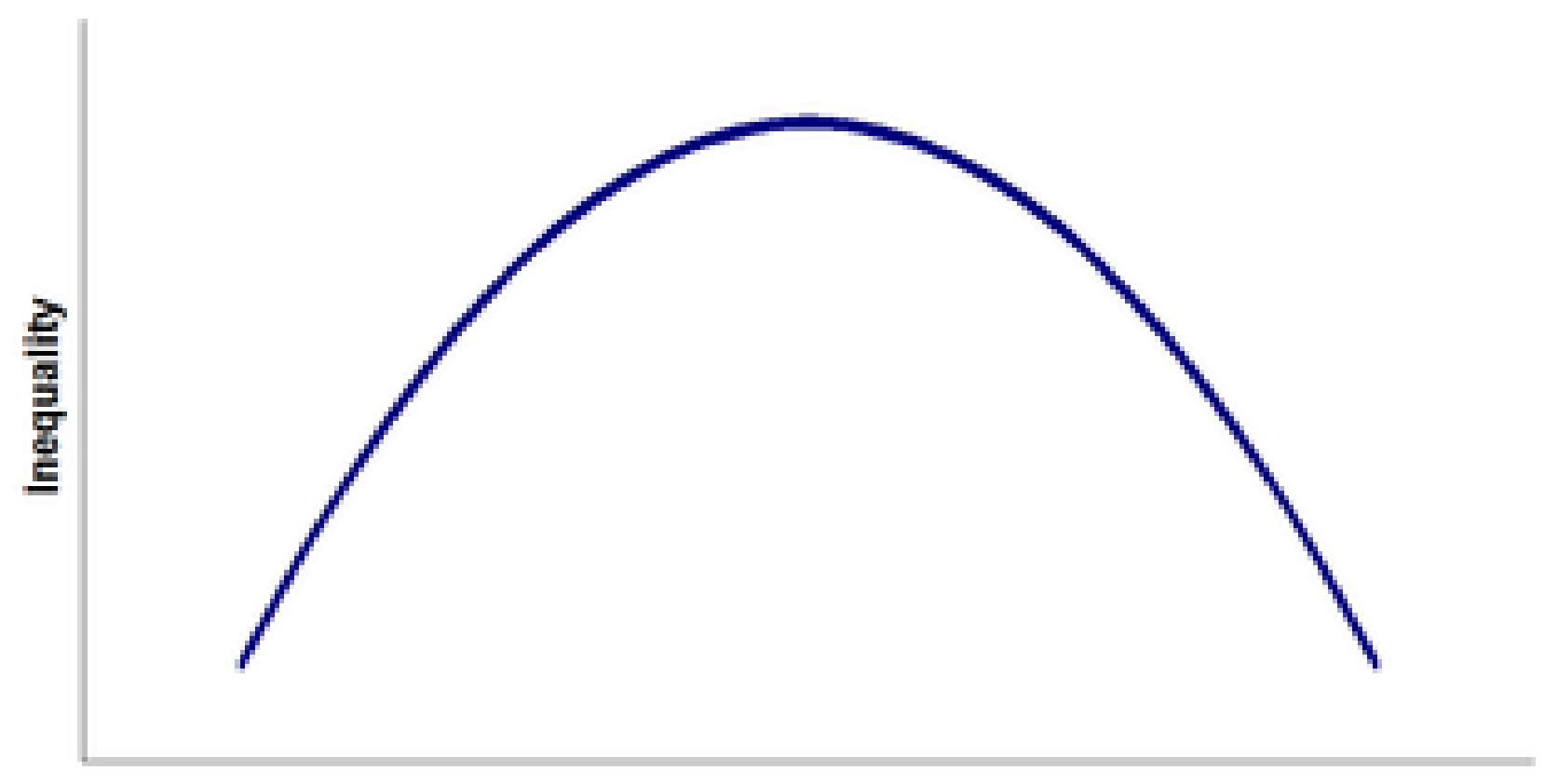

Income per Capita

Source: Adapted by the author from wnw. wikipedia.org

Having attempted to explain the concepts of sustainable development and gender, this paper ask the following research question: Is there correlation between gender equality and sustainable development? Is gender equality influences sustainable development in Central Africa? Does the relationship between men and women really channelized sustainable development in Central Africa countries? The main objective of this paper is to analyze the correlation between gender equality and sustainable development in Central Africa countries. In this paper we have used cross-sectional analysis (transversal analysis) and data from UNDP (2011). The structure of this paper is as follow: the next section reviews the literature. Section 3 presents the methodology (data sources, variables, method, and model specification). Section 4 analyses the empirical results and discussions, and the last section concludes.

\section{Literature Review}

The Commission on sustainable development (CSD) in 1997 noted that women across class, race, ethnicity and location have come to serve as catalysts for environmental and democratic activism. By that time women had already succeeded in gaining a "Principle" in the Rio Declaration and a Chapter in Agenda 21, "Global action for women towards sustainable and equitable development". 
Chapter 24 of the Agenda explicitly called upon governments to consider developing strategies by the year 2000 to eliminate constitutional, legal, administrative, cultural, behavioral, social and economic obstacles to the full participation of women in sustainable development and public life and to promote measures to give women better access to natural and financial resources. A number of practical initiatives have been initiated by women since the United Nations Conference on Environment and Development in Rio, 1992, and the Fourth United Nations Conference for the Advancement of Women in Beijing.

The Earth Summit in Rio de Janeiro in 1992 marked a decisive step in the direction of sustainable development. The international civil society, and specifically international women's movements, ascended to the global political stage in Rio as new political actors who succeeded in exerting significant normative influence on the drafting of summit documents. Emancipating approaches, such as empowerment and later gender mainstreaming as well, were developed and disseminated for the international conferences which followed Rio. The global conference Rio+10 offered the opportunity to focus on genderpolitical perspectives.

Sustainable development requires the full and equal participation of women at all levels (Hemmati and Gardiner, 2002). Gender equity is an essential building block in sustainable development. Indeed, none of the three "pillars" of sustainable development can be achieved without solving the prevailing problem of gender inequality (as measured by the economic participation, education, health and political empowerment of women). First, the environmental protection requires a solid understanding of women's relationship to natural and environmental resources, as well as their rights and roles in resource planning and management. Second, the economic well-being requires gender-sensitive strategies. $70 \%$ of the world's estimated 1.3 billion people living in absolute poverty are women. Segmentation of labor markets - horizontally and vertically has only marginally improved. Third, social equity is fundamentally linked to gender equity. Sexism, racism, discrimination on the grounds of ethnic group, faith, political opinion, social status and sexual orientation are clear indicators of social inequity.

Seminal studies and literatures over the past years related on sustainable development have emerged as the latest development catchphrase. A wide range of nongovernmental as well as governmental organizations have embraced it as the new paradigm of development (Lélé, 1991). A review of the literature that has sprung up around the concepts of gender and sustainable development indicates, 
however, a lack of consistency in their interpretation. More importantly, while the all-encompassing nature of the concepts gives it political strength, its current formulation by the mainstream of gender and sustainable development thinking contains significant weaknesses. These include an incomplete perception of the problems of poverty, vulnerability, environmental and natural resources, environmental degradation, confusion about the role of economic growth and about the concepts of sustainability and participation. How these weaknesses can lead to inadequacies and contradictions in policy making is demonstrated in the context of international trade, agriculture, and forestry. It is suggested that if sustainable development is to have a fundamental impact, politically expedient fuzziness will have to be given up in favor of intellectual clarity and rigor.

Many argue that rapid sustainable development is accompanied with the change in the environmental quality. Pioneering researchers such as Arrow et al., (1995) and Grossman and Krueger (1995) support the EKC hypothesis and show that there is an inverse $\mathrm{U}$ or $\mathrm{N}$ relationship, between some of the environmental indicator and per capita income. There are a numerous number of studies regarding this hypothesis. Actually, many of these studies critically examine this hypothesis. Stern, Common and Barbier (1996) critically examine the concept of the environmental Kuznets curve. Stern, Common and Barbier (1996) carry out simulations combining environmental Kuznets curve estimates from the literature with World Bank forecasts for economic growth for individual countries, aggregating over countries to derive the global impact. They propose that there is an inverted U-shape relation between environmental degradation and income per capita.. The inference from some such environmental Kuznets curve estimates that further development will reduce environmental degradation is dependent on the assumption that world per capita income is normally distributed when in fact median income is far below mean income.

Agras and Chapman (1999) estimate dynamic EKC relationship between income and carbon dioxide (CO2) and income/energy use (per capita consumption of energy), including energy prices, based on the stylized fact that total global emission of carbon dioxide increases or decreases with a change in oil price. As in Suri and Chapman (1998), they include the ratio of imports of all manufactured goods over domestic production of all manufactures and the ratio of exports of manufactured goods over domestic manufacturing. They find that there would be no evidence for EKC relationship between income and energy consumption if energy prices and trade variables are included in the estimation. 
Per capita income and emission level have a relationship. This relationship is unclear in researches. In this regard, Stern (2002) compares the decomposition model with the neoclassical production function assumption and standard EKC model, using nested method. The author finds that the results of decomposition model have better statistical properties. New empirical evidences have been provided by Mazzanti, Montini and Zoboli (2007) on delinking trends concerning emission-related indicators in Italy. The main contribution of these authors' paper is in providing EKC evidence exploiting environmental economic merged panel datasets at a decentralized level exploiting long time series and rich cross-section heterogeneity at both sectoral and provincial level.

The dependent variable Multidimensional poverty index (MPI) is a new index of acute multidimensional poverty (Alkire and Santos, 2010). It permits to channelize development in many dimensions. It reflects deprivations in very rudimentary services and core human functioning. Although deeply constrained by data limitations, the MPI reveals a different pattern of poverty than income poverty, as it illuminates a different set of deprivations. The MPI has three dimensions: health, education, and standard of living. These are measured using ten indicators. Poor households are identified and an aggregate measure constructed using the methodology proposed by Alkire and Foster (2007, 2009). Each dimension is equally weighted; each indicator within a dimension is also equally weighted. The independent variables: the Gini index capturing inequality (Gini index), the Gender inequality index and the environmental durability index (the composite measure of durability, the supply in primary resources and the pollution) are presented in the methodology section.

\section{Methodology}

First data used and variables related to the study are specified. Second the method and model are specified.

\subsection{Data used and Variables Specification}

This paper uses cross-sectional analysis or transversal analysis, and data from UNDP (2011), World Bank (2011) for the year 2010 to analyze the impact of gender on sustainable development in Central Africa countries. Central Africa in the larger sense, is made up of the Central African Economic Community (CEEAC), represents an enlargement of groups in Central Africa such as the Central African Monetary Community (CEMAC), Cameroon, Central African Republic, Chad, Equatorial Guinea, Congo, and Gabon; the Economic 
Community of the Great Lakes (CEPGL), made up of the Democratic Republic of the Congo, Burundi, Rwanda, Angola, and Sao Tome and Principe. In all, Central Africa is basically the Congo Basin.

The dependent variable Multidimensional poverty index (MPI) helps to capture the sustainable development. The Gini coefficient (also known as the Gini index or Gini ratio) is a measure of statistical dispersion. The Gender inequality index (GII) is a new index for measurement of gender disparity that was introduced in the 2010 by the United Nations Development Programme (UNDP). According to the UNDP, this index is a composite measure which captures the loss of achievement, within a country, due to gender inequality, and uses three dimensions to do so: reproductive health, empowerment, and labor market participation. The new index was introduced as an experimental measure to remedy the shortcomings of the previous, and no longer used, indicators, the gender development index (GDI) and the Gender empowerment measure (GEM).

The environmental durability index is composed as follow: the composite measure of durability (adjusted saving rate, ecological footprint and environmental performance index), the supply in primary resources (percentage of fossils fuels and percentage renewable fuels), emissions of $\mathrm{CO} 2$ (emissions of $\mathrm{CO} 2$ per capita and emissions of $\mathrm{CO} 2$ growth), and pollution (emissions of greenhouse gases per capita, urban pollution, depletion of natural resources, forestry areas, forestry areas evolution and endangered species).

The ecological footprint of a specified population or economy can be defined as the area of ecologically productive land (and water) in various classes cropland, pasture, forests, etc. - that would be required on a continuous basis first to provide all the energy/material resources consumed, and second to absorb all the wastes discharged by that population with prevailing technology, wherever on Earth that land is located. The environmental performance index (EPI) is a method of quantifying and numerically benchmarking the environmental performance of a country's policies. This index was developed from the pilot environmental performance index, first published in 2002, and designed to supplement the environmental targets set forth in the United Nation Millennium Development Goals. The EPI was preceded by the environmental sustainable index (ESI), published between 1999 and 2005. The ESI was developed to evaluate environmental sustainability relative to the paths of other countries. 
A greenhouse gas (GHG) is a gas in an atmosphere that absorbs and emits radiation within the thermal infrared range. This process is the fundamental cause of the greenhouse effect. The primary greenhouse gases in the Earth's atmosphere are water vapor, carbon dioxide methane, nitrous oxide, and ozone. In the Solar System, the atmospheres of Venus, Mars, and Titan also contain gases that cause greenhouse effects. Greenhouse gases greatly affect the temperature of the Earth. Without them, Earth's surface would be on average about $33 \mathrm{C}\left(59^{\circ} \mathrm{F}\right)$ colder than at present. However, since the beginning of the industrial revolution, the burning of fossil fuels has contributed to the increase in carbon dioxide in the atmosphere from $280 \mathrm{ppm}$ to $390 \mathrm{ppm}$, despite the uptake of a large portion of the emissions through various natural "sinks" involved in the carbon cycle. Anthropogenic carbon dioxide $\left(\mathrm{CO}_{2}\right)$ emissions (i.e., emissions produced by men and women activities) come from combustion of carbonaceous fuels, principally wood, coal, oil, and natural gas.

Urban pollution is a pollution of highly urban populated areas mainly deriving from motor vehicles, industrial plants, combustion and heating plants, etc. Rapid urbanization has resulted in increasing urban pollution in major cities, especially in developing countries. Air pollution in these cities is attributed to motorcycles and vehicle emissions brought about by high number of older vehicles coupled with poor vehicle maintenance, inadequate infrastructure and low fuel quality. While most developed countries have put in measures to reduce vehicle emissions, in terms of fuel quality and vehicle emission reduction technologies, these measures are yet to be adopted in most cities in Central Africa countries. Resource depletion is an economics term referring to the exhaustion of raw materials within a region. In Central Africa countries, one of the region producers of raw materials, natural resources are commonly divided between renewable resources and non-renewable resources. Use of either of these forms of resources beyond their rate of replacement is considered to be resource depletion. Resource depletion is most commonly used in reference to farming, fishing, mining, and fossil fuels.

\subsection{Method and Model Specification}

Two different types of data set had been used for investigations. The first and most used type was cross-sectional. This approach exams the actual new Multidimensional poverty index (MPI) and the environmental indicator relationship at one point in time across a whole set of countries. The second type of data set provides time-series within countries and examines how the MPI and environmental indicator relationship have changed over time in individual 
countries. This second type of data set is the best type for investigating the Kuznets relationship. But unfortunately, such historical data sets that were then available were usually of short time length or inter-temporal, making it difficult to draw useful conclusions from this sort of data set alone. In this research, sustainable development is captured by this new indicator which data are available only for the year 2010 .

Using a descriptive statistic analysis our method can be specified into three steps. First we estimate the causal relationship between dependent variable and the independent variables. This will permit us to verify the stylized facts. Second, the Gini index is obtained as follow:

$$
\text { Gini }=\frac{1}{n-1}\left[\frac{2 \sum_{i=1}^{n} i x_{(i)}}{n \bar{x}}-(n+1)\right]
$$

Where $x_{(i)}$ is the individual income range in increasing order, $n$ is the total individual number, and $\bar{x}$ is the mean of $\chi_{(i)}$. The Lorenz curves are draw with:

$$
q_{i}=\frac{\sum_{k=1}^{i} x_{(k)}}{\sum_{k=1}^{n} x_{(k)}}
$$

Where $q_{i}$ represents the increasing cumulated frequency and $x_{(k)}$ represent the MPI, GINII, GII and SDI range in increasing order.

The Gini equation will be used to draw the Lorentz curves and to analyze the effects of gender equality on sustainable development. And then, we construct the new sustainable development index at the last step. The formulation of the new sustainable development index is presented as follow:

$$
\begin{aligned}
S D I= & \frac{\bar{X}_{1}}{\overline{\bar{X}}} S R A+\frac{\bar{X}_{2}}{\overline{\bar{X}}} E F T+\frac{\bar{X}_{3}}{\overline{\bar{X}}} E P I+\frac{\bar{X}_{4}}{\overline{\bar{X}}} T F F+\frac{\bar{X}_{5}}{\overline{\bar{X}}} P R F+\frac{\bar{X}_{6}}{\overline{\bar{X}}} C O 2_{p c}+\frac{\bar{X}_{7}}{\overline{\bar{X}}} E C O 2_{g}+\frac{\bar{X}_{8}}{\overline{\bar{X}}} E G H G_{p c}+ \\
& \frac{\bar{X}_{9}}{\overline{\bar{X}}} U P+\frac{\bar{X}_{10}}{\overline{\bar{X}}} P N R+\frac{\bar{X}_{11}}{\overline{\bar{X}}} F A+\frac{\bar{X}_{12}}{\overline{\bar{X}}} F A E+\frac{\bar{X}_{13}}{\overline{\bar{X}}} E S
\end{aligned}
$$

Where, SDI is the sustainable development index, the dependent variable; $\bar{X}_{i}$ are the means of the variables $X_{i}$ related, $i=1,2, \ldots, 13 ; \overline{\bar{X}}$ is the mean of all the 
variables; $\frac{\bar{X}_{i}}{\overline{\bar{X}}}$ are parameters to be estimated representing the weight of the variables $X_{i}$ related with. $i=1,2, \ldots, 13$ The variables are: MPI the multidimensional poverty index, GINII the Gini index, GII the gender inequality index, SRA the adjusted saving rate, EFP the ecological footprint, EPI the environmental performance index, $P F F$ the percentage of fossils fuels, $P R F$ the percentage renewable fuels, $E C O 2_{p c}$ the emissions of $\mathrm{CO} 2$ per capita, $E C O 2_{g}$ the emissions of $\mathrm{CO} 2$ growth, $E G H G_{p c}$ the emissions of greenhouse gases per capita, $U P$ the urban pollution, DNR the depletion of natural resources, $F A$ the forestry areas, $F A E$ the forestry areas evolution, and $E S$ the endangered species.

\section{Empirical Results and Discussions}

In this section, we have documented the findings from our analysis in three phases. First we present the results of the causal relationship; secondly we present the different curves and last we present results from the new sustainable development index constructed.

Table 1 first presents the results of the simple regression analyzing the correlation between dependent variable and the independent variables.

Table 1: Results of the causal relationship between MPI and GINII

\begin{tabular}{r|rrrrrr}
\hline MPI & Coef & Std. Err. & $\mathrm{t}$ & $\mathrm{P}>|\mathrm{t}|$ & [95\% Conf. Interval ] \\
\hline GINII & -.0013341 & .0028408 & -0.47 & 0.650 &. .0077603 & .0050922 \\
- Cons & .4017935 & .1249403 & 3.22 & 0.011 & .119159 & .6844281 \\
\hline
\end{tabular}

Source: Author's calculation

Table 1 shows the causal relation between the dependent variable (MPI) and the independent variables (GINII). There is a negative correlation between the Gini index and the Multidimensional poverty index. When the Multidimensional poverty index increases inequality decreases. The amelioration of the population's well-being reduces the economic, social, and environmental inequality in Central Africa countries.

Table 2: Results of the causal relationship between MPI and GII

\begin{tabular}{r|rrrrrr}
\hline MPI & Coef & Std. Err & $\mathrm{t}$ & $\mathrm{P}>|\mathrm{t}|$ & {$[95 \%$ Conf. Interval] } \\
G GII & -.0005041 & .0019367 & -0.26 & 0.800 & -.0048853 & .003877 \\
\hline
\end{tabular}

Source: Author's calculation 
Table 2 presents the results of the simple regression and shows that there is a negative relationship between the MPI and the Gender inequality index. When the Multidimensional poverty index increases, the Gender inequality index decreases. This means that the economic participation of women, the education of women, the access to health and political empowerment of women increase. The interdependence test has not being conducted because of cross-section analysis. These results confirm the stylized facts. model:

In the second phase, curves are drawn according to the Lorentz curve's

Diagram 2: Curves of GINII, GII, and SDI

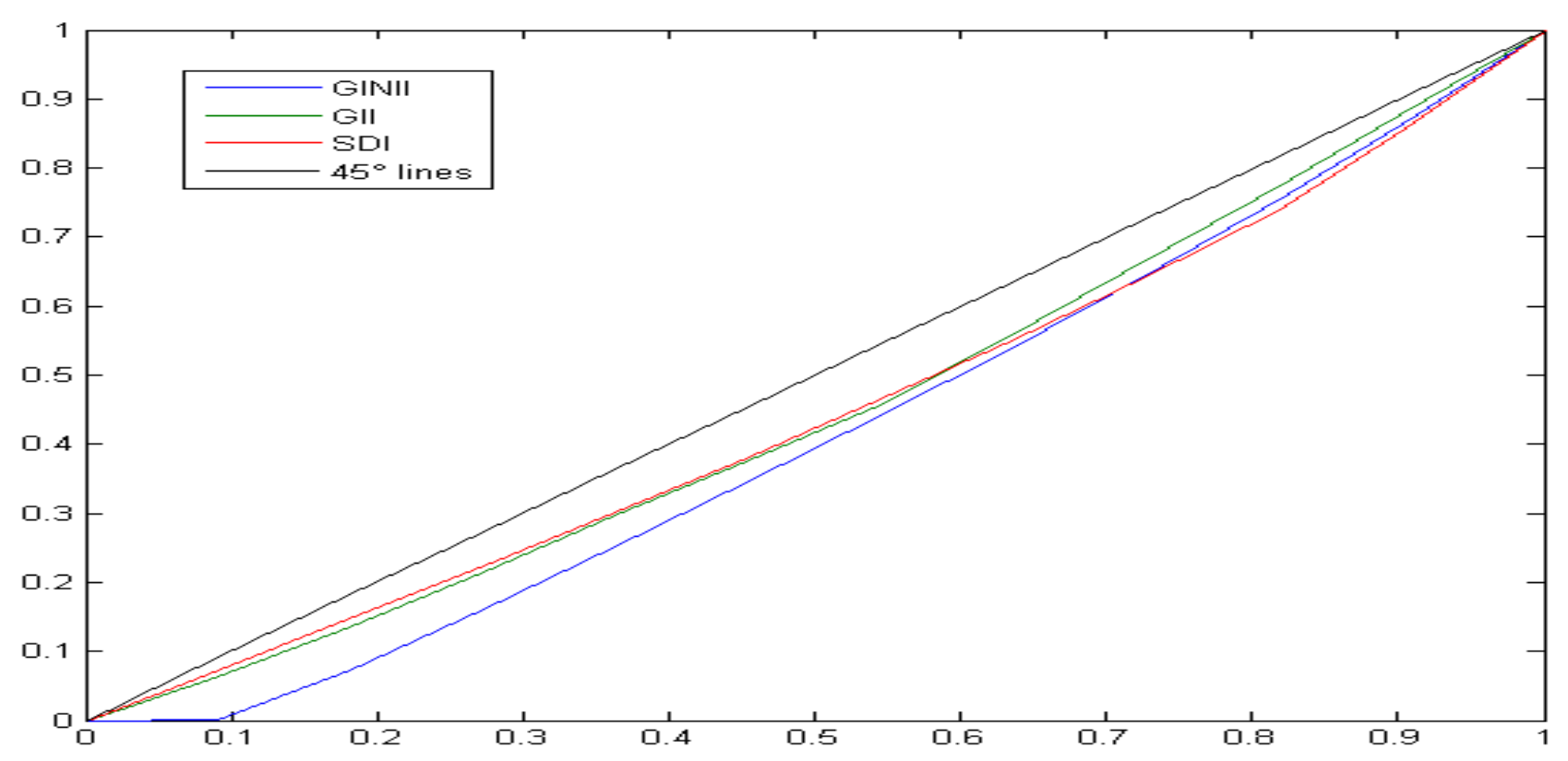

Source: Author's calculation

Diagram 2 shows the Lorenz curves for the Gini (GI), gender inequality (GII) and the sustainable development index (SDI). Overall inequality seems to be acute that the gender inequality and inequality attributed to sustainable development till the $70^{\text {th }}$ percentile. After this point, overall inequality reduces and become less that the SDI but not sufficient enough to overcome the GII. This means that the gender inequality index which capture the gender inequality and the sustainable development index which environmental problems are much closed. 
The results from our sustainable development index constructed are presented in Table 3 for the different Central Africa countries.

Table 3: Statistical figures of MPI, GINII, GII, and SDI

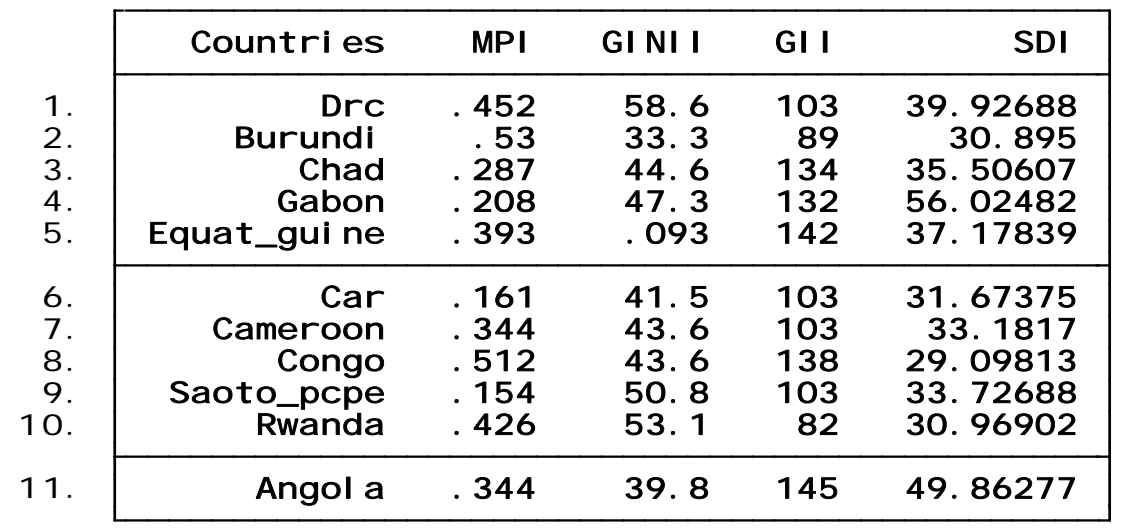

Source: Author's calculation

From table 3 statistic on Sustainable development index (SDI) are presented according to the relation (3). Countries like Gabon and Angola have the highest SDI and the Republic of Congo and Rwanda have the lowest SDI. This means that, countries with low SDI more integrated in their development process environmental problems for more sustainable development.

Thereon, we compute correlations for our different indexes to study their behavioral trends in Table 4.

Table 4: Results of the simple regression between MPI, GINII, GII, and SDI

\begin{tabular}{r|rrrr} 
& MPI & GINII & GII & SDI \\
\hline MPI & 1.0000 & & & \\
GINII & -0.1547 & 1.0000 & & \\
GI I & -0.0864 & -0.4242 & 1.0000 & \\
SDI & -0.3139 & 0.0394 & 0.5039 & 1.0000
\end{tabular}

Source: Author's calculation

Table 4 shows that there is a negative correlation between the sustainable development index and the Multidimensional poverty index. SDI is a synthetic environmental variable which has contrary effects on MPI but positive impacts on sustainable development. When the MPI increases the environmental problems are reduced, then ensuring sustainable development in all the 11 developing countries in Central Africa. 


\section{Conclusion}

The aim of this paper was to analyze the correlation between gender equality and sustainable development in Central Africa countries. Empirical lessons confirmed the relationship between the multidimensional poverty index, the Gini index, the gender inequality index, and the sustainable development index.

Better use of the Central Africa region's female population could reduce inequality and poverty, enhance economic, social and environmental well-being, increase economic growth, and help ensure sustainable development in all the 11 countries. Closing the gender gap in these countries depends on enlightened government policies which take gender equality dimensions into account. Findings show the impact of gender equality on sustainable development in Central Africa countries.

The main value added of this research is that it provides EKC evidence exploiting new indicators (MPI and GII) based on cross-sectional analysis. The evidence from this type of investigation is more informative than that from crosscountry studies which has dominated in the EKC literature so far, with rare exceptions. This line of thinking also has important implications for the models which integrated gender equality in sustainable development. One way to accomplish this is by estimating these relationships. This paper looks forward to the structural transformation of a developing economy.

\section{References}

[1] Agras, J. and Chapman, D. (1999), A Dynamic Approach to the Environmental Kuznets Curve Hypothesis, Ecological Economics, 28(2): 267-277.

[2] Alkire, S. and Foster, J. (2007), Counting and Multidimensional Poverty Measurement, Oxford Poverty and Human Development Initiative, Working Paper $\mathrm{n}^{\circ}$, Oxford Department of International Development, University of Oxford.

[3] Alkire, S. and Foster, J. (2009), Counting and Multidimensional Poverty, In Von Braun J. (Ed.) The Poorest and Hungry: Assessment, Analysis and Actions. Washington D.C.: International Food Policy Research Institute.

[4] Alkire, S. and Santos, M. E. (2010), Acute Multidimensional Poverty: A New Index for Developing Countries, Human Development Research Paper, 2010/11, UNDP

[5] Arrow, K. B., Bolin, R., Costanza, P., Grossman, G. M. and Krueger, A. B. (1995), Economic Growth and the Environment, Quarterly Journal of Economics, 110(2): 353377. 
[6] Daly, H. E. (1973), Towards a Steady State Economy. San Francisco: Freeman. Daly, H. E. 1991. Steady-State Economics (2nd edition). Washington, D.C.: Island Press.

[7] Giddings, B., Hopwood, B. and O’Brien, G. (2002), Environment, economy and society: fitting them together into sustainable development, Sustainable Development, 10(4): 187-196

[8] Grossman, G. M. and Krueger, A. B. (1995), Economic growth and the environment, Quarterly Journal of Economics, 110: 353-377.

[9] Hemmati, M. and Gardiner, R. (2002), Gender and Sustainable Development, World Summit Papers of the Heinrich Böll Foundation, $n^{\circ} 10$, march

[10] Kuznets, S. (1955), Economic growth and income inequality. American Economic Review, 45: 1-28.

[11] Lélé, S. M. (1991), Sustainable development: A critical review, World Development, 19(6): 607-621

[12] Mazzanti, M., Montini, A. and Zoboli, R. (2007), Economic Dynamics, Emission Trends and the EKC Hypothesis New Evidence Using NAMEA and Provincial Panel $\begin{array}{llllll}\text { Data for } & \text { Italy. Nota } & \text { di } & \end{array}$ http://www.feem.it/Feem/Pub/Publications/WPapers.

[13] Meadows, D. H., Meadows, D. L., Randers, J. and Behrens, III W. W. (1972), The Limits to Growth, Universe Books, New York.

[14] Sen Gita (1999), Gender Mainstreaming in Finance. A Reference Manual for Governments and Other Stakeholders. London: Commonwealth Secretariat.

[15] Stern, D. I., Common, M. S. and Barbier, E. B. (1996), Economic growth and environmental degradation: The environmental Kuznets curve and sustainable development, World Development, 24(7): 1151-1160

[16] Stivers, R. I. (1976), The sustainable Society: Ethics and Economics growth Westminster Press, 240 p.

[17] Suri, V. and Chapman, D. (1998), Economic Growth, Trade and Energy: Implication for the Environmental Kuznets Curve. Ecological Economics. 25(2): 195-208.

[18] UNDP (2011), Human Development Reports (HDR) 1995-2011, New York: UNDP.

[19] United Nations (1987), Report of the World Commission on Environment and Development. General Assembly Resolution 42/187.

[20] World Bank (2008), World Development Indicators 2008, Oxford University Press. World Bank (2011), World Development Indicators, Washington, DC : World Bank.

[21] Yandle, B., Vijayaraghavan, M. and Bhattarai, M. (2002), The Environmental Kuznets Curve: A primer, The Property and Environment Research Center (PERC) Research Study 02-01. 
